\title{
Development of a Novel Epoxy Resin Having Cardo Structure
}

\author{
Yuichiro Tokoro, Yudai Yaginuma, and Toshiyuki Oyama* \\ Department of Advanced Chemistry, Yokohama National University, \\ 79-5 Tokiwadai, Hodogaya-ku, Yokohama 240-8501, Japan \\ *oyama-toshiyuki-wz@ynu.ac.jp
}

\begin{abstract}
A novel epoxy resin (E-NP-BPDA) having the cardo structure derived from the phthalein dye was prepared from 3,4'-biphthalic anhydride (a-BPDA). a-BPDA was reacted with phenol in methanesulfonic acid, affording a cardo structure. Fixation of the cardo structure was achieved by reaction with methylamine in which cyclic ester was converted to cyclic amide. Further reaction with epichlorohydrin gave E-NP-BPDA. Thermal analysis revealed that E-NP-BPDA has both high thermal stability $\left(T_{\mathrm{d} 5}=301^{\circ} \mathrm{C}\right)$ and a low softening point $\left(T_{\mathrm{sp}}\right.$ $=109^{\circ} \mathrm{C}$ ) probably due to the low symmetry and the cardo structure. Curing E-NP-BPDA with slightly excess phenol novolac in the presence of tetraphenylphosphonium tetraphenylborate (TPP-MK) by heating up to $200{ }^{\circ} \mathrm{C}$ afforded a dark brown thermoset with almost no epoxy groups indicated by IR spectra. The glass transition temperature of the thermoset evaluated by DMA reached $192{ }^{\circ} \mathrm{C}$ and the value was higher than that of the conventional phenol-novolac-cured bisphenol-A-type epoxy resin.
\end{abstract}

Keywords: Epoxy resin, Cardo structure, Phthalein dye, Thermal stability

\section{Introduction}

Epoxy resins have been widely applied to adhesives, coatings, electronic materials and building materials due to their prominent thermal, mechanical and electrical properties [1]. Generic epoxy resins are mainly derived from bisphenol A (BPA) and phenol novolac (PN). Thermal stability and toughness of their thermosets are, however, insufficient to advanced materials, e.g. composite materials for airplanes and sealant for highperformance LSI. A strategy to improve thermal stability of epoxy resins is introducing polycyclic aromatic rings. For instance, epoxy thermosets derived from naphthalene [2-7], anthracene [8,9] and xanthene [10] showed higher thermal stability as well as higher toughness and lower moisture absorption than those derived from BPA and phenol. The highly symmetric polycyclic moieties, however, raised melting point of epoxides, leading to difficulty in mold fabrication.

In this work, we designed an epoxy resin having low symmetry and cardo structure which lower the melting point and increase solubility by reducing molecular packing [11-14]. As a suitable building block with low symmetry, 3,4'-biphthalic anhydride (a-BPDA) was employed because reaction of the phthalic anhydride moiety with phenols afforded cardo structure as can be seen in phthalein dyes. The properties of epoxy resins and thermosets derived from a-BPDA were investigated by thermal analysis.

\section{Experimental}

\subsection{Materials}

Phenol novolac (phenolite TD-2131) and 1-(2cyanoethyl)-2-ethyl-4-methylimidazole (2E4MZ$\mathrm{CN}$ ) were kindly donated by DIC corporation and Shikoku Chemicals corporation, respectively. Bis(tetrabutylphosphonium) pyromellitate (BTBP$\mathrm{PM}$ ) and tetraphenylphosphonium tetraphenylborate (TPP-MK) were kindly donated by Hokko Chemical Industry Co., Ltd. Phenol, epichlorohydrin, tetramethylammonium chloride and aBPDA were purchased from Tokyo Chemical Industry Co., Ltd. Aqueous methylamine solution (40 wt $\%$ ), hydrochloric acid and sodium hydroxide were purchased from FUJIFILM Wako Pure Chemical Corporation. Methanesulfonic acid was purchased from Kanto Chemical Co., Inc. 


\subsection{Measurement}

The ${ }^{1} \mathrm{H}$ and ${ }^{13} \mathrm{C}$ NMR spectra were recorded with a Bruker BioSpin DRX300 (300 MHz) spectrometer and a JEOL ECX-400 spectrometer $(400 \mathrm{MHz})$ at room temperature using dimethyl sulfoxide- $d_{6}$ as a solvent and tetramethylsilane as an internal standard. Molecular weight was determined with size exclusion chromatography (SEC) using a Tosoh TSK $_{\text {gel }} \mathrm{GMH}_{\mathrm{HR}}-\mathrm{M}$ column coupled with UV and RI detectors (Tosoh, UV-8020 and RI-8021), and DMF containing $\mathrm{LiBr}(30 \mathrm{mmol} / \mathrm{L})$ and phosphoric acid $(60 \mathrm{mmol} / \mathrm{L})$ as a mobile phase. The SEC system was calibrated by using polystyrene standards. Thermogravimetric analysis (TGA) and differential scanning calorimetry (DSC) were carried out on Shimadzu TGA-50 and DSC-60, respectively, at a heating rate of $10{ }^{\circ} \mathrm{C} / \mathrm{min}$ under a nitrogen flow. Thermomechanical analysis (TMA) was carried out on Shimadzu TMA-60 at a heating rate of $5{ }^{\circ} \mathrm{C} / \mathrm{min}$ under a nitrogen flow. Dynamic mechanical analysis (DMA) was conducted on SII nanotechnology DMS-6100 by dual cantilever bending at a heating rate of $5{ }^{\circ} \mathrm{C} / \mathrm{min}$ under air with a frequency of $1 \mathrm{~Hz}$. Infrared (IR) spectra were recorded by using a Perkin Elmer SPECTRUM ONE spectrometer and $\mathrm{KBr}$ pellet method.

\subsection{Synthesis of P-BPDA [15]}

A solution of a-BPDA $(10.0 \mathrm{~g}, 34.0 \mathrm{mmol})$ and phenol $(16.9 \mathrm{~g}, 170 \mathrm{mmol})$ in methanesulfonic acid (24.8 mL, $382 \mathrm{mmol}$ ) was stirred at $90{ }^{\circ} \mathrm{C}$ for $48 \mathrm{~h}$ under Ar. After cooling to room temperature, the mixture was added to ice/water $(500 \mathrm{~mL})$. The precipitate was collected by filtration to give a reddish brown solid (18.4 g, 85\%). ${ }^{1} \mathrm{H}$ NMR (300 MHz, DMSO- $\left.d_{6}\right): \delta=9.67(-\mathrm{OH}, 2.9 \mathrm{H}), 8.08-7.45$ (Ar-H, 6.0H), 7.20-6.52 (- $\left.\mathrm{C}_{6} \mathrm{H}_{4}-\mathrm{OH}, 12.0 \mathrm{H}\right) \mathrm{ppm}$. FT-IR (KBr): 3385, 1740, 1613, 1596, 1514, 1443, $1364,1300,1271,1238,1175,1133,1100,1053$, $961,930,837 \mathrm{~cm}^{-1}$.

\subsection{Synthesis of NP-BPDA [16]}

A solution of P-BPDA (15.0 g, $23.5 \mathrm{mmol})$ and $40 \%$ aqueous methylamine $(339 \mathrm{~mL}, 3.61 \mathrm{~mol})$ was stirred at room temperature for 21 days. The reddish purple mixture was added to conc. $\mathrm{HCl}$ (4.6 mol)/water $(7 \mathrm{~L})$. The pale blue precipitate was collected by filtration and dissolved in methanol $(160 \mathrm{~mL})$. The solution was added to water $(3.2 \mathrm{~L})$ and collected by filtration to give a pale blue solid $(15.1 \mathrm{~g}, 97 \%) .{ }^{1} \mathrm{H}$ NMR (300 MHz, DMSO- $\left.d_{6}\right): \delta=$ $9.67(-\mathrm{OH}, 2.5 \mathrm{H}), 8.92-7.40(\mathrm{Ar}-\mathrm{H}, 6.0 \mathrm{H}), 7.01-$ $6.73\left(-\mathrm{C}_{6} \mathrm{H}_{4}-\mathrm{OH}, 11.5 \mathrm{H}\right) 2.75-2.62\left(-\mathrm{N}\left(\mathrm{CH}_{3}\right)_{2}, 4.4\right.$
H) ppm. FT-IR (KBr): 3374, 1704, 1663, 1613, $1595,1513,1445,1385,1269,1245,1176,1116$, $1066,1038,1014,969,925,890,835 \mathrm{~cm}^{-1}$.

\subsection{Synthesis of E-NP-BPDA [17]}

A solution of NP-BPDA $(10.0 \mathrm{~g}, 15.1 \mathrm{mmol})$, epichlorohydrin $(84.9 \mathrm{~g}, 0.918 \mathrm{~mol})$ tetramethylammonium chloride (1.26 g) and a droplet of water was stirred at $80^{\circ} \mathrm{C}$ for $8 \mathrm{~h}$ under Ar. After cooling to $40{ }^{\circ} \mathrm{C}$, aqueous $\mathrm{NaOH}(20 \mathrm{wt} \%, 45.9 \mathrm{~g})$ was added to the mixture, followed by stirring at $40{ }^{\circ} \mathrm{C}$ for $15 \mathrm{~h}$. The mixture was neutralized by aqueous acetic acid (20 wt\%, $55.2 \mathrm{~g})$, extracted by dichloromethane, washed by water and brine, and concentrated. The residue was added to hexane. The precipitate was collected by filtration, extracted by THF and concentrated to give a pale orange solid (12.8 g, 96\%). ${ }^{1} \mathrm{H}$ NMR (300 MHz, DMSO- $\left.d_{6}\right): \delta=$ 8.08-7.28 (Ar- $\mathrm{H}, \quad 6.0 \mathrm{H}), \quad 7.15-6.44 \quad\left(-\mathrm{C}_{6} \mathrm{H}_{4}-\mathrm{O}-\right.$, $11.5 \mathrm{H}), 4.31(2.8 \mathrm{H}), 3.95-3.70(3.1 \mathrm{H}), 2.89-2.62$ (9.9H) ppm. FT-IR (KBr): 3455, 3060, 3003, 2929, 2883, 1728, 1680, 1638, 1608, 1584, 1509, 1469, $1449,1421,1378,1289,1252,1180,1155,1120$, $1062,1034,990,969,913,834 \mathrm{~cm}^{-1}$.

2.6. General procedure for preparation of thermosets

A solution of E-NP-BPDA (epoxy equivalent weight $(\mathrm{EEW})=259 \mathrm{~g} / \mathrm{eq}, 0.15 \mathrm{~g}$ ), PN (hydroxy equivalent weight $(\mathrm{HEW})=104 \mathrm{~g} / \mathrm{eq}, 0.5-1.2 \mathrm{eq})$ and TPP-MK (1.5 mg, $1 \mathrm{phr})$ in acetone $(1.5 \mathrm{~mL})$ was evaporated in vacuo. The residue was put into an aluminium mold. The curing process was done for $130^{\circ} \mathrm{C}(2 \mathrm{~h}), 160{ }^{\circ} \mathrm{C}(3 \mathrm{~h}), 180^{\circ} \mathrm{C}(3 \mathrm{~h})$ and 200 ${ }^{\circ} \mathrm{C}(5 \mathrm{~h})$ to give a dark brown thermoset.

\section{Results and discussion}

\subsection{Synthesis}

The reaction of a-BPDA with phenol in methanesulfonic acid followed by addition to water gave P-BPDA as a reddish brown solid (Scheme 1). No signals from a-BPDA were observed in ${ }^{1} \mathrm{H}$ NMR and IR spectra. The signals from aromatic and hydroxy groups of the phenol moieties emerged around 7.0 and $9.7 \mathrm{ppm}$, respectively, in the ${ }^{1} \mathrm{H}$ NMR spectrum (Fig. 1). Relative integrals of the protons indicated that three phenol moieties were introduced to one a-BPDA on average. Formation of the cardo structure was confirmed by ${ }^{13} \mathrm{C}$ NMR signals of quaternary carbons at $90-93 \mathrm{ppm}$.

In order to protect the cardo structure, the cyclic ester groups of P-BPDA were converted to the amide groups by aqueous methylamine solution. 
After 21 days, color of the reaction mixture changed from purple to reddish purple. Repeated precipitation into dilute hydrochloric acid and water afforded a pale blue solid (NP-BPDA). Almost quantitative reaction was confirmed by the signals from $N$ methyl groups around $2.7 \mathrm{ppm}$ and relative integrals in the ${ }^{1} \mathrm{H}$ NMR spectrum. Shift of signals of quaternary carbons from $90-93 \mathrm{ppm}$ to $73-75 \mathrm{ppm}$ in the ${ }^{13} \mathrm{C}$ NMR spectra and shift of the carbonyl peak from $1740 \mathrm{~cm}^{-1}$ to $1663 \mathrm{~cm}^{-1}$ in the IR spectra supported formation of the cyclic amide having the cardo structure.
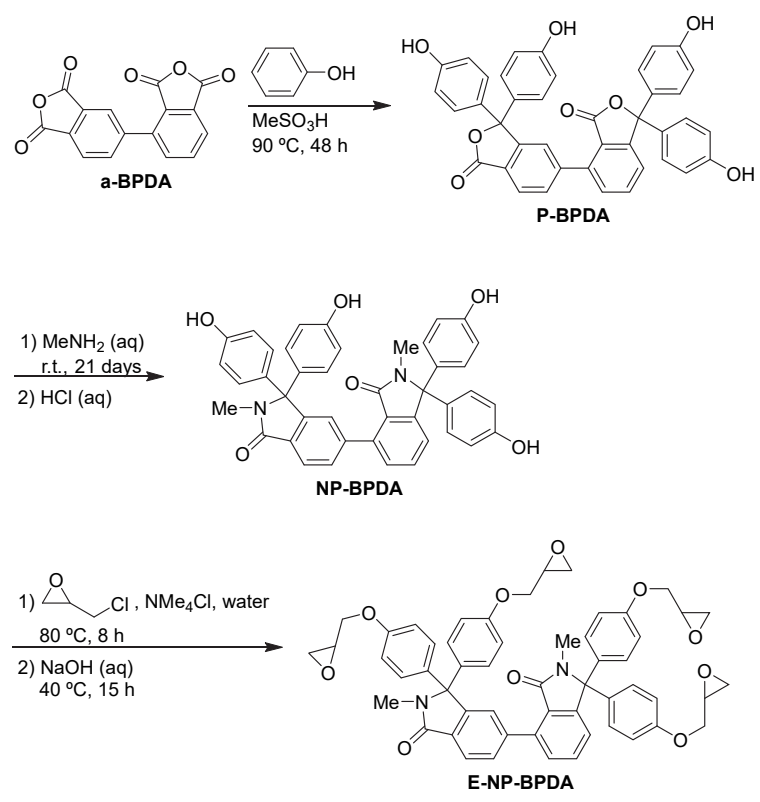

Scheme 1. Synthesis of E-NP-BPDA.

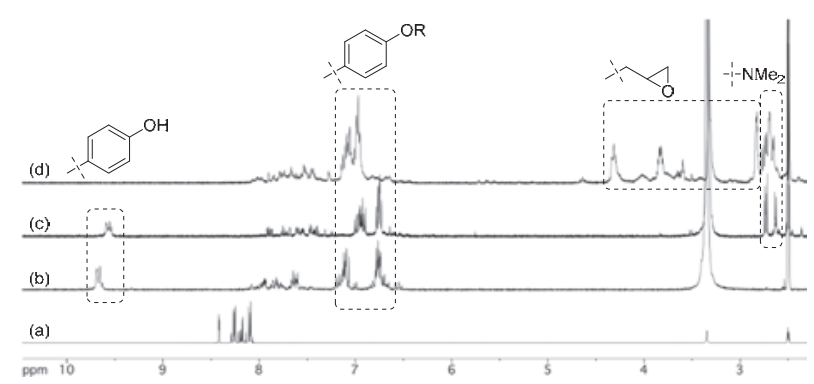

Fig. 1. ${ }^{1} \mathrm{H}$ NMR spectra of (a) a-BPDA, (b) P-BPDA, (c) NP-BPDA and (d) E-NP-BPDA (DMSO- $d_{6}$, r.t.).

Glycidyl groups were introduced by reaction of NP-BPDA in epichlorohydrin containing tetramethylammonium chloride as a phase-transfer catalyst, followed by addition of aqueous $\mathrm{NaOH}$. In ${ }^{1} \mathrm{H}$ NMR spectrum of the product (E-NP-BPDA), the signals from hydroxy groups $(\sim 9.6 \mathrm{ppm})$ disappeared and those from glycidyl groups emerged between 2.6 and $4.3 \mathrm{ppm}$. Minor ${ }^{1} \mathrm{H}$ NMR signals around the main glycidyl peaks and size exclusion chromatogram indicated that E-NP-BPDA contains some oligomeric species. EEW of E-NP-BPDA was determined as $259 \mathrm{~g} /$ eq by back titration with $\mathrm{NaOH}$ after the addition reaction of epoxy groups with $\mathrm{HCl}$. The EEW was slightly larger than the value estimated as each hydroxyl group reacted to one epichlorohydrin (246 g/eq), which coincided with detection of oligomers by SEC.

\subsection{Properties of E-NP-BPDA}

No remarkable weight loss was observed under $250{ }^{\circ} \mathrm{C}$ by TGA $\left(T_{\mathrm{d} 5}=301{ }^{\circ} \mathrm{C}\right)$, indicating that ENP-BPDA can be subjected to thermal curing condition. A weak peak at $80{ }^{\circ} \mathrm{C}$ and a softening point at $109{ }^{\circ} \mathrm{C}$ observed by DSC and TMA thermograms, respectively, suggested melting or glass transition of E-NP-BPDA around $100{ }^{\circ} \mathrm{C}$ (Fig. 2 ). The fluidity was, however, insufficient in melting and blending with curing agent and accelerators. Due to high solubility of E-NP-BPDA to methylene chloride, acetone, DMF and THF, we decided that E-NP-BPDA, curing agents and curing accelerators were blended in acetone.

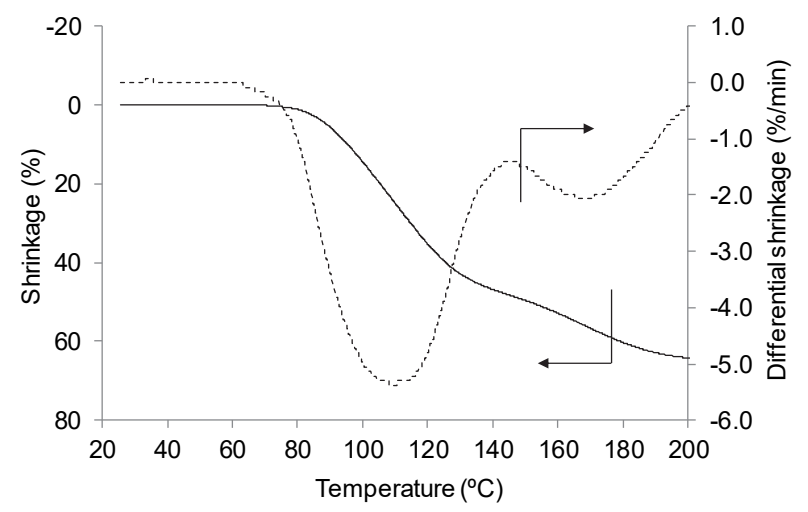

Fig. 2. TMA thermogram of E-NP-BPDA $\left(5^{\circ} \mathrm{C} / \mathrm{min}\right.$, under $\mathrm{N}_{2}$ ).

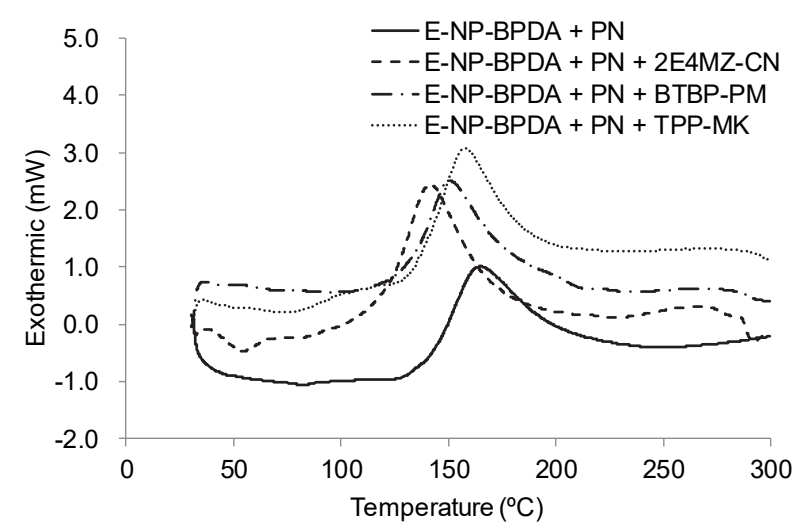

Fig. 3. DSC thermograms of the mixtures containing ENP-BPDA, PN and curing accelerators $\left(10^{\circ} \mathrm{C} / \mathrm{min}\right.$, under $\mathrm{N}_{2}$ ). 


\subsection{Preparation and properties of thermosets}

Since a mixture of E-NP-BPDA (1.0 eq) and PN $(1.0 \mathrm{eq})$ showed an exothermic peak $(+103 \mathrm{~J} / \mathrm{g})$ with an onset of $125^{\circ} \mathrm{C}$ (Fig. 3), the mixture was subjected to curing for $130{ }^{\circ} \mathrm{C}(2 \mathrm{~h})$ and $160{ }^{\circ} \mathrm{C}(3 \mathrm{~h})$. However, the remained peak $\left(913 \mathrm{~cm}^{-1}\right)$ from epoxy group in IR spectrum of the thermoset indicated insufficient conversion of E-NP-BPDA. Adding higher-temperature processes as $130{ }^{\circ} \mathrm{C}(2 \mathrm{~h}), 160$ ${ }^{\circ} \mathrm{C}(3 \mathrm{~h}), 180{ }^{\circ} \mathrm{C}(3 \mathrm{~h})$ and $200{ }^{\circ} \mathrm{C}(5 \mathrm{~h})$ improved the conversion, but residual epoxy group was still present after curing.

Thus, curing accelerators for E-NP-BPDA/PN were screened by measuring DSC of the resin mixtures (Fig. 3). 2E4MZ-CN and BTBP-PM lowered the onsets of the exothermic peaks to $84{ }^{\circ} \mathrm{C}$ and $98{ }^{\circ} \mathrm{C}$, respectively, which may induce undesired curing during preparation of the mixture and molding. In contrast, the onset temperature $\left(125^{\circ} \mathrm{C}\right)$ and heat value $(98 \mathrm{~J} / \mathrm{g})$ of the mixture with TPP-MK were high enough to prepare the thermoset. Moreover, the peak temperature $\left(157^{\circ} \mathrm{C}\right)$ was lower than that of the mixture without accelerators (165 ${ }^{\circ} \mathrm{C}$ ), implying acceleration of curing by TPP-MK.

After curing of a mixture containing E-NPBPDA (1.0 eq), PN (1.0 eq) and TPP-MK (1 phr) for $130{ }^{\circ} \mathrm{C}(2 \mathrm{~h}), 160{ }^{\circ} \mathrm{C}(3 \mathrm{~h}), 180{ }^{\circ} \mathrm{C}(3 \mathrm{~h})$ and $200{ }^{\circ} \mathrm{C}$ $(5 \mathrm{~h})$, the peak from epoxy groups $\left(913 \mathrm{~cm}^{-1}\right)$ disappeared in IR spectrum of the obtained thermoset (E-NP-BPDA/PN1.0/TPP) (Fig 4). Increasing the amount of PN to 1.1 eq (E-NP-BPDA/ PN1.1/TPP) and 1.2 eq (E-NP-BPDA/PN1.0/TPP) also resulted in high conversion of epoxy groups of E-NP-BPDA.

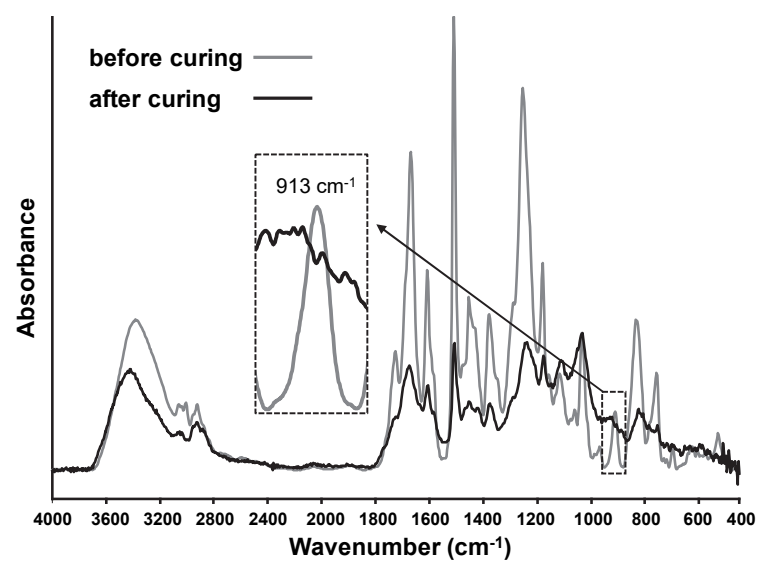

Fig. 4. IR spectra of the mixture and thermoset of E-NPBPDA (1.0 eq), PN (1.0 eq) and TPP-MK (1 phr) (KBr disk).

Thermal stability of those thermosets was evaluated by TGA under a nitrogen flow. The $5 \mathrm{wt} \%$ degradation temperatures $\left(346-358^{\circ} \mathrm{C}\right)$ were typical values for epoxy thermosets. TMA thermograms of the thermosets revealed their high softening points $\left(T_{\mathrm{sp}} \mathrm{s}\right)$ above $200{ }^{\circ} \mathrm{C}$. Glass transition temperature $\left(T_{\mathrm{g}}\right)$ of E-NP-BPDA/PN1.1/TPP, which showed the highest $T_{\mathrm{sp}}$, was evaluated by DMA and was found to be $192{ }^{\circ} \mathrm{C}$ (Fig. 5). The value was higher than $T_{\mathrm{g}}$ of the conventional phenol-novolac-cured BPAtype epoxy thermoset (DGEBA/PN). The rigid structure of E-NP-BPDA constructed by benzene rings probably contributed to raise the glass transition temperature.

Table 1. Thermal properties of cured epoxy resins.

\begin{tabular}{lcccc}
\hline Epoxy resins $^{\mathrm{a}}$ & $\begin{array}{l}T_{\mathrm{d} 5}{ }^{\mathrm{b}} \\
\left({ }^{\circ} \mathrm{C}\right)\end{array}$ & $\begin{array}{l}T_{\mathrm{d} 10} \mathrm{~b} \\
\left({ }^{\circ} \mathrm{C}\right)\end{array}$ & $\begin{array}{l}\text { Char yield }{ }^{\mathrm{b}} \\
(\%)\end{array}$ & $\begin{array}{l}T_{\mathrm{g}}^{\mathrm{c}} \\
\left({ }^{\circ} \mathrm{C}\right)\end{array}$ \\
\hline $\begin{array}{l}\text { E-NP-BPDA/ } \\
\text { PN1.0/TPP }\end{array}$ & 346 & 379 & 45 & - \\
$\begin{array}{l}\text { E-NP-BPDA/ } \\
\text { PN1.1/TPP }\end{array}$ & 352 & 385 & 42 & 192 \\
$\begin{array}{l}\text { E-NP-BPDA/ } \\
\text { PN1.2/TPP }\end{array}$ & 358 & 389 & 44 & - \\
\hline
\end{tabular}

${ }^{\mathrm{a}}$ Curing condition: $130{ }^{\circ} \mathrm{C} / 2 \mathrm{~h}+160{ }^{\circ} \mathrm{C} / 3 \mathrm{~h}+180^{\circ} \mathrm{C} /$ $3 \mathrm{~h}+200^{\circ} \mathrm{C} / 5 \mathrm{~h} .{ }^{\mathrm{b}}$ By TGA. ${ }^{\mathrm{c}}$ By DMA.

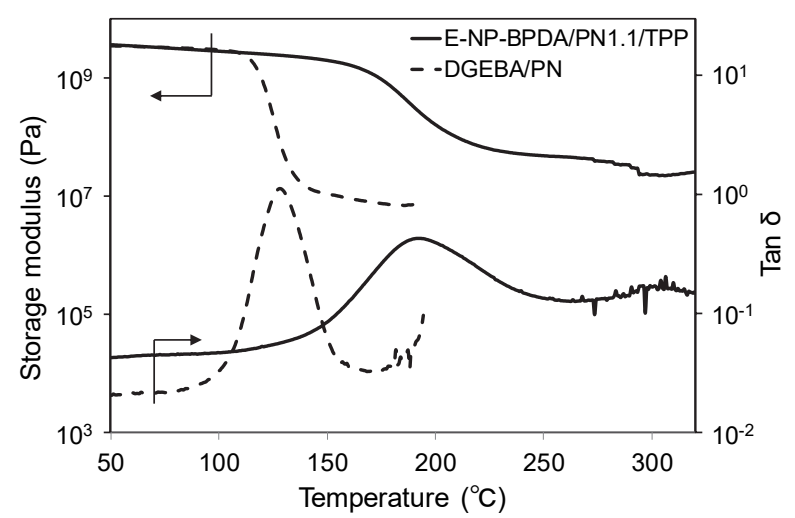

Fig. 5. DMA thermograms of E-NP-BPDA/PN1.1/TPP and DGEBA $/ \mathrm{PN}\left(5^{\circ} \mathrm{C} / \mathrm{min}\right.$, under air).

\section{Conclusion}

Introduction of phenol moieties to a-BPDA under acidic condition gave a phenolphthalein derivative (P-BPDA) with low symmetry and the cardo structure. Following reactions with methylamine and with epichlorohydrin afforded an epoxy resin (E-NP-BPDA) with high solubility, low softening point $\left(T_{\mathrm{sp}}=109^{\circ} \mathrm{C}\right)$ and high thermal stability $\left(T_{\mathrm{d} 5}\right.$ $=301{ }^{\circ} \mathrm{C}$ ) which were suitable to molding and curing. Curing the mixture of E-NP-BPDA, PN and TPP-MK reached almost full conversion of epoxy groups, affording dark brown thermosets. The thermosets showed high glass transition temperature of $192{ }^{\circ} \mathrm{C}$ in DMA thermogram. 


\section{References}

1. F.-L. Jin, X. Li, and S.-J. Park, J. Ind. Eng. Chem., 29 (2015) 1.

2. T. Fukunaga, K. Ogami, K. Nakahara, M. Kaji, and T. Endo, J. Network Polym. Jpn., 30 (2009) 142.

3. G. Pan, Z. Du, C. Zhang, C. Li, X. Yang, and H. Li, Polymer, 48 (2007) 3686.

4. H. Ren, J. Sun, B. Wu, and Q. Zhou, Polymer, 47 (2006) 8309.

5. K. Xu, M. Chen, X. Zhang, and K. Zhang, Macromol. Chem. Phys., 205 (2004) 1559.

6. M. Kaji and T. Endo, J. Polym. Sci. Part A: Polym. Chem., 37 (1999) 3063.

7. J. Y. Lee and J. Jang, J. Polym. Sci. Part A: Polym. Chem., 37 (1999) 419.

8. M. Kaji, K. Ogami, and T. Endo, J. Appl. Polym. Sci., 72 (1999) 953.
9. Y. Ohnishi, T. Oyama, and A. Takahashi, Kobunshi Ronbunshu, 68 (2011) 62.

10. I. Ogura, T. Imada, and Y. Takahashi, J. Network Polym. Jpn., 24 (2003) 206.

11. G.-S. Liou, H.-J. Yen, and H.-Y. Lin, J. Polym. Sci. Part A: Polym. Chem., 45 (2007) 4352.

12. G. Latha and S. C. Murugavel, Polym. Bull., 73 (2016) 3237.

13. X. Xiong, P. Chen, Q. Yu, N. Zhu, B. Wang, J. Zhang, and J. Li, Polym. Int., 59 (2010) 1665.

14. D.-J. Liaw, B.-Y. Liaw, J.-J. Hsu, and Y.-C. Cheng, J. Polym. Sci. Part A: Polym. Chem., 38 (2000) 4451.

15. R. W. Sabnis, Tetrahedron Lett., 50 (2009) 6261.

16. P. W. Morgan, J. Polym. Sci. Part A: Polym. Chem., 2 (1964) 437.

17. W. Zhang, T. Iijima, W. Fukuda, and M. Tomoi, J. Network Polym. Jpn., 18 (1997) 59. 